\title{
Pseudoepitheliomatous hyperplasia in trophic ulcers in leprosy patients. A 28-case study
}

\author{
M.-Y. GRAUWIN, I. MANE \& J.-L. CARTEL \\ Institut de Léprologie Appliquée (ILAD) BP 11023 Dakar \\ CD Annexe, Sénégal
}

Accepted for publication 13 February 1996

\begin{abstract}
Summary Between 1984 and 1993, pseudoepitheliomatous hyperplasia developing in chronic ulcers were observed in 28 former Senegalese leprosy patients, which amounts to an annual frequency of 1.9 per 1000 ulcers. Correct diagnosis could only be made by histopathological examination of specimens taken from the depth of the lesion. Amputation was carried out on 17 patients and local excision on the other 10. Recurrence of growth was observed in 8 of the 10 patients treated by excision; in all of these 8 cases below knee amputation had to be subsequently performed. From our experience, it may be assumed that local excision should be carried out only in the case of small tumours. Since the aim of surgical procedure is to allow the patient to have physical autonomy, below knee amputation, followed by adaptation of prosthesis, should be the procedure chosen in the other cases.
\end{abstract}

\section{Introduction}

Several papers have shown that malignant tumour may develop in plantar ulcers with an annual frequency of about 2 per 1000 ulcers. ${ }^{1-4}$ Nonmalignant proliferative lesions, with the appearance of fungating growths, may also develop in chronic ulcers. The diagnosis of these tumours, which are pseudoepitheliomatous hyperplasia (often called cauliflower growths), is not easy since, clinically, it is not possible to distinguish them from squamous-cell carcinoma. Moreover, the results of histopathological examination may differ according to the site in the lesion where the biopsy specimen is taken. The aim of the present paper is to report on our experience in Senegal where 28 cases of pseudoepitheliomatous hyperplasia developing in plantar ulcers in leprosy patients were diagnosed and treated between 1984 and 1993.

\section{Material and methods}

In Senegal, a country in West Africa with about 8 million inhabitants, the leprosy control programme is under the supervision of the medical doctor responsible for the 
public health activities in each of the 10 administrative regions of the country. The medical coordinator of the programme is based at the Direction of Public Health Services in Dakar, the capital of Senegal. The Institut de Léprologie Appliquée (ILAD), where all the study patients were hospitalized and treated, is also located in Dakar. The Institute is responsible for the development of field-applied research programmes on leprosy, and also for the training of the physicians, the specialized nurses and the other technicians involved in the leprosy programme. It is also in charge of the specialized care of the leprosy patients hospitalized because they suffer reaction, neuritis or other consequences of the leprosy. Several physicians, including a surgeon, work full-time at the Institute.

In 1994, all the patients who had been hospitalized and treated at the Institute between 1984 and 1993 because they were suffering a pseudoepitheliomatous hyperplasia developed in plantar ulcers or in trophic ulcers of the leg were brought in for re-examination. At the moment of the initial hospitalization, the growths were examined for site, size, bleeding on palpation, signs of inflammation and involvement of regional lymph nodes. In all cases a biopsy specimen was taken from the growth before a surgical procedure. All biopsies were sent to the Institut Pasteur in Dakar for histopathological examination. Different surgical procedures were adopted depending on the result of the histopathological examination, and the site and extent of the growth.

\section{Results}

During the 10-year study period (1984-93), 66 patients were examined at ILAD because they presented a proliferative lesion developing, either in plantar ulcers or in trophic ulcers of the leg or the hand. The diagnosis of pseudoepitheliomatous hyperplasia was made for 31 of the 66 patients. There were 22 males and 9 females with a median age of 53 years; the lesion was observed in plantar ulcers in 29 of them and in chronic ulcers of the leg in the remaining 2 . The period of time elapsed between the onset of ulcer and the appearance of growth ranged from 1 to 37 years (average 11.5 years).

The 32 tumours (one patient had two plantar ulcers, each with one tumour) presented a similar macroscopic aspect with several or all the following signs: prolif erative lesion located in the fore-foot (14 cases), mid-foot ( 7 cases), heel ( 9 cases) and ankle ( 2 cases), size ranging from 5 to $12 \mathrm{~cm}$, slight bleeding, infection, enlargement of inguinal lymph nodes. All the patients complained of pain at the site of the lesion. In all 32 cases, the result of the histopathological examination made on the biopsy specimen showed pseudoepitheliomatous hyperplasia, without signs of malignancy: hyperkeratosis of the epidermis slight or absent, no malignant mitotic figures and intact basement membrane. A second histopathological examination was performed in tissues taken from the depth of the lesion at the moment of the surgical procedure: in 3 cases the diagnosis was squamous cell carcinoma. The study population is therefore of 28 patients.

One patient died of gangrene before surgery. The following surgical procedures were carried out on the 27 remaining patients with pseudoepitheliomatous hyperplasia: above knee amputation in 2 cases, below knee amputation in 15 cases, fore-foot amputation in 1 case and local excision in 10 cases. Recurrence of the growth was observed in 8 of the $10(80 \%)$ patients treated by local excision after a delay ranging from 2 months to 3 years 
Table 1. Follow-up of 26 patients with pseudoepitheliomatous hyperplasia treated at ILAD between 1984 and 1993

\begin{tabular}{|c|c|c|c|c|c|c|c|}
\hline Case & Age & Sex & $\begin{array}{l}\text { Duration } \\
\text { of ulcer }\end{array}$ & $\begin{array}{c}1 \mathrm{st} \\
\text { treatment }\end{array}$ & $\begin{array}{c}\text { Follow-up } \\
\text { (years) }\end{array}$ & $\begin{array}{l}\text { 2nd } \\
\text { treatment }\end{array}$ & $\begin{array}{c}\text { Follow-up } \\
\text { (years) }\end{array}$ \\
\hline 1 & 50 & M & 10 & AK amputation* & dead $0 \cdot 10$ & & \\
\hline 2 & 60 & $\mathrm{~F}$ & 20 & Excision & 3 & & \\
\hline \multirow[t]{2}{*}{$3 \ddagger$} & 54 & M & 5 & BK amputation $\dagger$ & $2 \cdot 3$ & & \\
\hline & & & 3 & Excision & $2 \cdot 3$ & & \\
\hline 4 & 60 & $\mathrm{~F}$ & 37 & BK amputation & 17 & & \\
\hline 5 & 45 & M & 2 & AK amputation & $3 \cdot 4$ & & \\
\hline 6 & 35 & $\mathrm{~F}$ & 5 & Excision & Recurrence PEH $2 \cdot 3$ & BK amputation & 3 \\
\hline 7 & 55 & M & 2 & BK amputation & $5 \cdot 9$ & & \\
\hline 8 & 64 & M & 10 & BK amputation & dead 4 & & \\
\hline 9 & 68 & M & 7 & Excision & Recurrence PEH 0.7 & BK amputation & $6 \cdot 8$ \\
\hline 10 & 38 & $\mathrm{~F}$ & - & BK amputation & 6 & & \\
\hline 11 & 55 & $\mathbf{M}$ & 20 & BK amputation & $5 \cdot 10$ & & \\
\hline 12 & 35 & M & 6 & Excision & Recurrence PEH $3 \cdot 1$ & BK amputation & $4 \cdot 8$ \\
\hline 13 & 60 & M & 10 & BK amputation & $7 \cdot 9$ & & \\
\hline 14 & 67 & M & 2 & Excision & Recurrence PEH 0.5 & BK amputation & $2 \cdot 2$ \\
\hline 15 & 58 & M & 4 & BK amputation & $8 \cdot 11$ & & \\
\hline 16 & 59 & $\mathrm{~F}$ & 20 & BK amputation & $8 \cdot 3$ & & \\
\hline 17 & 51 & M & - & BK amputation & $10 \cdot 1$ & & \\
\hline 18 & 58 & $\mathrm{~F}$ & 13 & BK amputation & $1 \cdot 6$ & & \\
\hline 19 & 46 & $\mathrm{~F}$ & 3 & Excision & Recurrence PEH 0.2 & BK amputation & $7 \cdot 8$ \\
\hline 20 & 40 & M & 3 & BK amputation & 1 & & \\
\hline 21 & 46 & $\mathbf{M}$ & 3 & BK amputation & dead 0.9 & & \\
\hline 22 & 72 & $\mathbf{M}$ & 1 & Lisf ranc amputation & $7 \cdot 6$ & & \\
\hline 23 & 60 & $\mathrm{~F}$ & 20 & Excision & Recurrence PEH 0.5 & BK amputation & $5 \cdot 8$ \\
\hline 24 & 57 & M & 32 & Excision & Recurrence PEH 0.2 & BK amputation & $5 \cdot 10$ \\
\hline 25 & 62 & M & 30 & Excision & Recurrence PEH 0.4 & BK amputation & $6 \cdot 11$ \\
\hline 26 & 66 & M & 20 & BK amputation & $5 \cdot 2$ & & \\
\hline
\end{tabular}

* above knee amputation;

† below knee amputation;

$\ddagger$ patient with pseudoepitheliomatous hyperplasia $(\mathrm{PEH})$ in each foot.

(average 11 months). In all of the 8 cases of recurrence, below knee amputation was then carried out.

By the end of 1994, data were available for 26 of the 27 patients (Table 1). Three of them had died. In one case the death was related neither to leprosy nor to a possible evolution of the tumour. The remaining two patients had died 9 and 10 months respectively after the surgical procedure (above knee amputation for one and below knee amputation for the other). In these two cases, the clinical picture, at the moment of death, was that of extensive cancer with pulmonary and inguinal and crural metastasis.

\section{Discussion}

The first point arising from our data is that the development of proliferative lesions, and, more especially, of pseudoepitheliomatous hyperplasia, in plantar ulcers does not occur as rarely as has been previously reported. It has been estimated that, in Senegal 
during the study period of 1984-93, the annual population of former leprosy patients with trophic ulcers was about 1500, therefore, the annual frequency of pseudoepitheliomatous hyperplasia developing in plantar ulcers may be estimated at 1.9 per 1000 ulcers.

Regarding diagnosis, it must be emphasized that the 28 patients of the present study were part of a larger series of 66 elderly leprosy patients who were hospitalized and examined at ILAD because they presented a proliferative lesion, developing in a preexisting trophic ulcer and suspected to be a malignant transformation. The diagnosis of pseudoepitheliomatous hyperplasia could be made only by histopathological examination. This statement is in agreement with the observation made by other authors, ${ }^{5,6}$ that it is impossible to distinguish clinically these malignant-looking tumours from carcinoma, which also develop in pre-existing ulcers. In our study, two patients died of an obvious consequence of their tumour, less than one year after the surgical procedure (amputation in both cases). Since the evolution was that of a malignant tumour, these were very probably two cases of squamous cell carcinoma misdiagnosed at histopathological examination. Such a result, together with the fact that in 3 other cases the answer of histopathological examination was pseudoepitheliomatous hyperplasia when made on a biopsy taken from the edge of the lesion, and squamous cell carcinoma when made on tissues from the depth of the lesion, clearly shows that correct diagnosis is not easy to ensure. It is essential, therefore, that the histopathological examination should be performed on several specimens of the lesion and, most importantly, that the diagnosis should not rely upon the results of histopathological examination of a peripheral biopsy.

Regarding the evolution of these tumours, our results are not essentially different from those presented by Srinivasan et al. or Swamy et al. ${ }^{5,6}$ but, regarding the line of treatment, we do not draw the same conclusion. These authors reported on series of 9 and 71 cases of pseudoepitheliomatous hyperplasia, respectively, in whom overall recurrence of the tumour was of about $20 \%$; in our series, it was of $28 \%$. However, the recurrence of growth was high in the patients treated by local excision, both in the series reported by Swamy (7 out of 18 patients, $39 \%$ ) or in ours ( 8 out of 10 patients, $80 \%$ ). These figures raise the question of the management of such tumours and, also, raise the question of the best surgical procedure to be adopted. A conservative approach in the treatment of cauliflower growths has been advocated in order to avoid mutilative surgery for the patient who is already handicapped by leprosy. ${ }^{5}$ But this recommendation was made mainly because it was assumed that malignancy is uncommon in cauliflower growths. From our data, it is clear that pseudoepitheliomatous hyperplasia represent only $40 \%$ of proliferative lesions arising in plantar ulcers, while carcinoma represent the remaining $60 \%$. It should be kept in mind that the aim of the surgical procedure is, in the case of pseudoepitheliomatous hyperplasia, to allow the patient to have physical autonomy. Deep and wide excision often results in such anatomical damage to the footbone that walking is impossible; moreover the adaptation of prosthesis is also impossible. On the other hand, local excision is followed by amputation because of the recurrence of growth in a large number of cases ( $80 \%$ in our series). Therefore, the choice of conservative surgical procedure is questionable. In fact, from our experience, one may assume that local excision should be carried out only in the case of small tumours (less than $3 \mathrm{~cm}$ ) and that below knee amputation, followed by adaptation of prosthesis, should be the procedure chosen in the other cases. 


\section{References}

${ }^{1}$ Grauwin M-Y, Gentile B, Chevallard A, Cartel J-L. Cancérisation des plaies chroniques plantaires chez les anciens malades de la lèpre. Acta Lepr, 1994; 9: 25-30.

2 Job CK, Riedel RG. Squamous cell carcinoma arising in plantar ulcers in leprosy. Int J Lepr, 1964; 32: 37-44.

3 Leiker DL. Skin carcinoma and leprosy. Trop Geogr Med, 1961; 13: 14-19.

${ }^{4}$ Richardus JH, Smith TC. Squamous cell carcinoma in chronic ulcers in leprosy: a review of 38 consecutive cases. Le pr Rev, 1991; 62: 381-388.

${ }^{5}$ Srinivasan H, Desikan KV. Cauliflower growths in neuropathic plantar ulcers in leprosy patients. $J$ Bone Joint Surg, 1971; 53: 123-132.

6 Swamy S, Durai V, Oomen PK, Rao KS. Cauliflower growths in trophic ulcers of leprosy. A 10-year study. Ind J Lepr, 1986; 58: 48-53. 